\title{
Psoriasis in Pregnancy
}

\author{
Altantuul D and Delgermaa $S^{*}$ \\ MNUMS of Nursing school, Mangolian \\ *Corresponding author: Delgermaa S, MNUMS of Nursing school, Mangolia
}

\section{ARTICLE INFO}

Received: 慧 December 16, 2019

Published: 㗀 January 09, 2020

Citation: Altantuul D, Delgermaa S. Psoriasis in Pregnancy. Biomed J Sci \& Tech Res 24(3)-2020. BJSTR. MS.ID.004056.

\section{ABSTRACT}

Psoriasis is a complex inflammatory disease, and in women the incidence is high in child-bearing years. Treatment during pregnancy presents genuine challenges since management requires adequate assessment of the extent of disease, comorbidity, and potential risk to the fetus. Scientific evidence is scarce on the effects that certain drugs have on fetal development given the ethical concerns about enrolling pregnant women in clinical trials. This review presents up-to-date information on the course of psoriasis during gestation and discusses associated conditions and the therapeutic protocols recommended for use during pregnancy.

Keywords: Psoriasis; Pregnancy; Topical Treatment

\section{Introduction}

Psoriasis is a chronic, complex, multifactorial inflammatory disease that affects both sexes equally. The mean age of onset in women is around 28 years, and $75 \%$ of female patients develop psoriasis before they are 40 years old, meaning that the majority of women are in their childbearing years at the time of diagnosis. The women with psoriasis had an increased risk of preterm birth and low birth weight in the univariate analysis (OR, 1.89; 95\% CI, 1.06-3.39), and the association remained statistically significant in the multivariate analysis. No association was found between psoriasis and rate of spontaneous abortion, cesarean delivery, or preeclampsia. As more information becomes available, we will gain a better understanding of the reciprocal relationship between pregnancy and psoriasis and the prevalence of potentially modifiable risk factors. This increased knowledge will help to optimize pregestational care in women with psoriasis and reduce the risk of gestational complications and fetal damage. In the next section, we will review the scientific evidence available on the use of different treatments for psoriasis during pregnancy [1-4].
This copy is for personal use. Any transmission of this document by any media or format is strictly prohibited. $738 \mathrm{~V}$. Ruiz et al. associated comorbidities, and disease severity. The women with psoriasis had an increased risk of preterm birth and low birth weight in the univariate analysis (OR, 1.89; 95\% CI, 1.06-3.39), and the association remained statistically significant in the multivariate analysis. No association was found between psoriasis and rate of spontaneous abortion, cesarean delivery, or preeclampsia. As more information becomes available, we will gain a better understanding of the reciprocal relationship between pregnancy and psoriasis and the prevalence of potentially modifiable risk factors. This increased knowledge will help to optimize pregestational care in women with psoriasis and reduce the risk of gestational complications and fetal damage (Table 1). We performed a systematic literature search to identify rel-evant studies. Our search yielded 362 publications using theterms "psoriasis and pregnancy" and 243 publications usingthe terms "psoriasis treatment and pregnancy". We thensearched for each treatment used in psoriasis in combina-tion with the terms "pregnancy" and "lactation". 
Table 1: Distribution and Odds Ratios (OR-s) for Low Birth Weight. Preterm Delivery. Cesarean Delivery. small. f or-Age Neonates, Preeclampsia. and [clamour). Cornpanng 13167 Mothers With and Without Psoriasis (2001-2003).

\begin{tabular}{|c|c|c|c|c|c|c|}
\hline & \multicolumn{2}{|c|}{ Mothers in Control Group } & \multicolumn{2}{|c|}{ Mothers with Mild Psoriasis } & \multicolumn{2}{|c|}{ Mothers with Severe Nonni\% } \\
\hline & No. & $\%$ & No. & $\%$ & No. & $\%$ \\
\hline \multicolumn{7}{|c|}{ Variable } \\
\hline Low birth weight & 667 & 6. & 50 & 6. & 51 & 8. \\
\hline OR $(95 \% \mathrm{Cl})$ & 1.00 & & $1.08(0.80-1.451$ & & $1.42(1.06 .1 .91)$ & \\
\hline Preterm delivery & 826 & 7. & 68 & 8. & SO & 8. \\
\hline OR $(95 \% \mathrm{CI})$ & 1.00 & & 1_17 (0.98-1.40) & & $1.07(0.96-1.19)$ & \\
\hline Small-for-aye neonate & 1817 & 16. & 133 & 16. & 107 & 17. \\
\hline OR (951 Cli & 1.00 & & 1.0610 .871 .281 & & $1.08(0.87-1.341$ & \\
\hline Cesarean delivery & 4019 & 34. & 286 & 35 & 242 & 38. \\
\hline OR (951 CI) & 1.00 & & 1.0310 .891 .191 & & $1.15(0.98 \bullet 1.35)$ & \\
\hline Preeclompsta o eclampslia & 140 & 11 & 8 & 1.0 & 8 & 1. \\
\hline OR $(95 \%$ CO & 1.00 & & $0.82(0.40 .1 .67)$ & & $1.04(0.51 .2 .13)$ & \\
\hline
\end{tabular}

\section{References}

1. Lima X, Janaki Raman V, Hughes M, Kimball AJ (2012) The impact of psoriasis on pregnancy outcomes. Invest Dermatol 132: 85-91.

2. Murase J, Chan KK, Garite TJ, Cooper DM, Weinstein GD (2005) Arch Dermatol. Hormonal effecr on psoriasis in pregnancy and post-partum 141: 601-606.

\section{ISSN: 2574-1241}

DOI: $10.26717 / B J S T R .2020 .24 .004056$

Delgermaa S. Biomed J Sci \& Tech Res

(c) (P) This work is licensed under Creative

Submission Link: https://biomedres.us/submit-manuscript.php
3. Tauscher AE, Fleischer AB, Phelps KC, Feldman SR (2002) Psriasis and pregnancy. J Cutan Med Surg pp. 561-570.

4. Raychaudhuri SP, Navare T, Gross J, Raychaudhuri SK (2003) Clinical course of psoriasis during pregnancy. Int I Dermatol 42(7): 518-520.

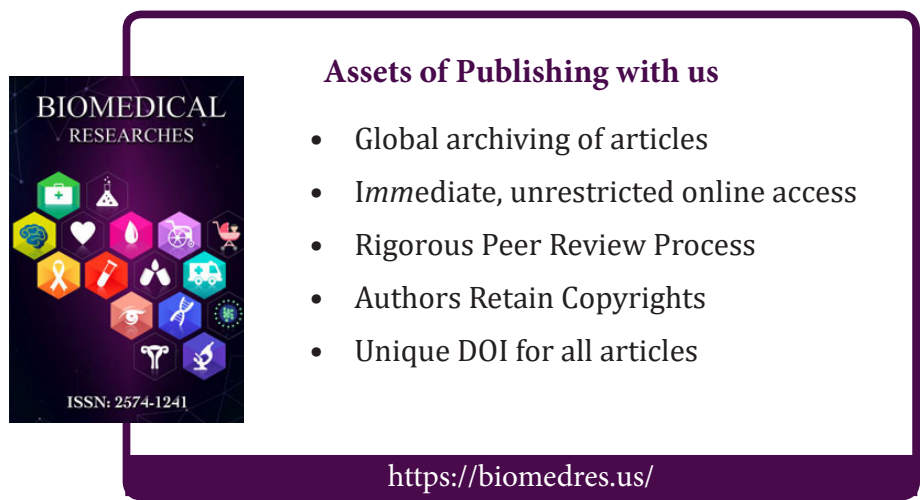

